\title{
LETTER
}

\section{Appearance of as-grown $c$ face in the internal texture of high-quartz crystals collected from Nagatani, Nose-town, Osaka Prefecture}

\author{
Norimasa SHIMOBAYASHI, Yu KoDAMA and Masaki TAKAYA \\ Department of Geology and Mineralogy, Graduate School of Science, Kyoto University, Kitashirakawa Oiwake-cho, \\ Sakyo-ku, Kyoto 606-8502, Japan
}

\begin{abstract}
Natural quartz crystals are composed of the rhombohedral $r\{10.1\}, z\{01.1\}$ and prizm $m\{10.0\}$ faces. Highquartz exhibits a hexagonal bipyramidal habit with no prism faces or rarely small prism faces. In either lowquartz or high-quartz, the appearance of a basal $c\{00.1\}$ faces is extremely rare. It has been shown that the faces from the exceptional localities where quartz crystals with basal faces occur have developed by dissolution or overgrowth on the mechanically-broken surface. In the present study, high-quartz crystals with a basal pinacoid from Nagatani, Nose-town, Osaka Prefecture were investigated by means of SEM-CL, and the growth band implying that the $c$-faces should be directly developed by an original growth process, neither by a dissolution process nor by overgrowth on the broken surface, was first found.
\end{abstract}

Keywords: High-quatrz, Morphology, Cathodoluminescence, Basal face, Nagatani

\section{INTRODUCTION}

Crystal morphology gives information about the formation process and environmental conditions of the crystals. Quartz, one of the main constituent minerals in the earth's crust, commonly preserve relic features such as external morphology and internal texture, because of its durability and resistance to weathering, both chemically and physically. Surface microtopography has allowed to examine the growth and dissolution mechanism at the last stage of crystallization, while internal texture such as growth zoning can give an information about the time-dependent change of isochronal surfaces and heterogeneity on the surface.

Natural quartz crystals (low-quartz; belonging to a trigonal crystal system) are mostly composed of the rhombohedral $r\{10.1\}, z\{01.1\}$ and prizm $m\{10.0\}$ faces. The appearance of a basal $c\{00.1\}$ faces is extremely rare in nature, although they are common in synthetic quartz crystals grown using seed crystals. The periodic bond chain (PBC) analysis (Hartman and Perdock, 1955), which can qualitatively predict the equilibrium and growth forms of crystal from crystal structure, has shown

doi:10.2465/jmps.131022b

N. Shimobayashi, shimo@kueps.kyoto-u.ac.jp Corresponding author that the $r, z$, and $m$ faces are smooth $\mathrm{F}$-faces (flat surface; where the layer-by-layer growth is expected) for the lowquartz (Hartman, 1959), whereas $c$ face is a rough surface, or a K-face (kink surface) (Hartman, 1965). Since F-faces usually grow slower than $\mathrm{K}$-faces, the expected growth habit of quartz should be bounded only by these smooth faces. This growth habit expected by the PBC analysis is not far from actual growth habits of natural low-quartz. However, there are exceptional several localities where quartz crystals with basal faces occur; for example amethyst crystals with $c$ faces found at the Four Peaks Mine, Arizona, USA. The surface microtopography of the basal $c$ faces and internal inhomogeneities of these crystals were investigated by Kawasaki et al. (2006). They concluded that the $c$ faces of these crystals from this locality have developed by dissolution on surfaces that were first mechanically broken and overgrown. Similar overgrowth process was reported on the internal texture of double terminated quartz crystals from Sichuan (China) revealed by the CL technique (Hashimoto et al., 2003).

Since high-quartz (belonging to a hexagonal crystal system) essentially has the same structure as low-quartz, the similar external morphology bounded by such F-faces can be expected. However, high-quartz crystals usually exhibit a hexagonal bipyramidal habit with no prism faces or rarely small prism faces. Such a hexagonal bipyramidal 
form of high-quartz seems to be the morphology formed in acidic magmas because the prism faces appear for quartz crystals synthesized hydrothermally at temperatures even above $573{ }^{\circ} \mathrm{C}$ (Hosaka et al., 1995). Highquartz crystals commonly exhibit rounded forms due to the dissolution process during the eruption of host magmas. Sunagawa and Sugibuchi (1986) carried out surface microtopography of the high-quartz crystals from a tuff bed, and a dacite lava of Miocene age at Goroku near Sendai, Miyagi Prefecture. They described that the highquartz crystals grew by the spiral growth mechanism, and then experienced by a short dissolution period by disequilibrium before the transition to low-quartz by quenching. Kitamura et al. (1992) observed the internal texture of the high-quartz crystals of this area by using a cathodoluminescence (CL) imaging system based on a scanning electron microscope (SEM-CL). They showed that each crystal has suffered the dissolution several times during the crystals grew. Asada et al. (2002) studied morphology and internal textures of negative crystals in high-quartz by combining microscopic observation and annealing experiments of high-quartz crystals from several localities. They estimated the equilibrium forms of high-quartz crystals, i.e., the rounded bipyramidal shape, suggesting that only $r$ faces are singular under the growth conditions of quartz crystals in felsic magmas. The prism faces of high-quartz change their surface structure to be rough un- der the conditions of felsic magma in contrast with expectation of the PBC analysis.

In spite of several studies on the high-quartz, the zonal structure and then the growth history of high-quartz have been poorly understood. As well as low-quartz, the appearance of basal $c\{00.1\}$ faces is extremely rare also in high-quartz crystals. Probably only one occurrence of high-quartz crystals with a basal pinacoid has been reported from Nagatani, Nose-town, Osaka Prefecture, Japan (Takada and Suesugi, 2004). In the present study, highquartz crystals with a basal pinacoid from this locality were investigated by means of SEM-CL, and the growth band implying that the $c$-faces should be directly developed by a growth process, not by a dissolution process, was first found.

\section{SAMPLES}

The samples used are euhedral crystals of high-quartz collected from the Sasori tuff breccia of the Arima Group and/or rhyolite dykes intruding into the Arima Group in the area of Nagatani, Nose-town, Osaka Prefecture. The Arima Group, whose total thickness is about 2000 meters, is part of voluminous felsic volcanic rocks of Late Cretaceous age extending in the Inner Zone of southwest Japan (Matsuura et al., 1995). The Sasori tuff breccia (biotite $\mathrm{K}$-Ar age: $70.9 \pm 3.5 \mathrm{Ma}$ ) corresponds to the uppermost
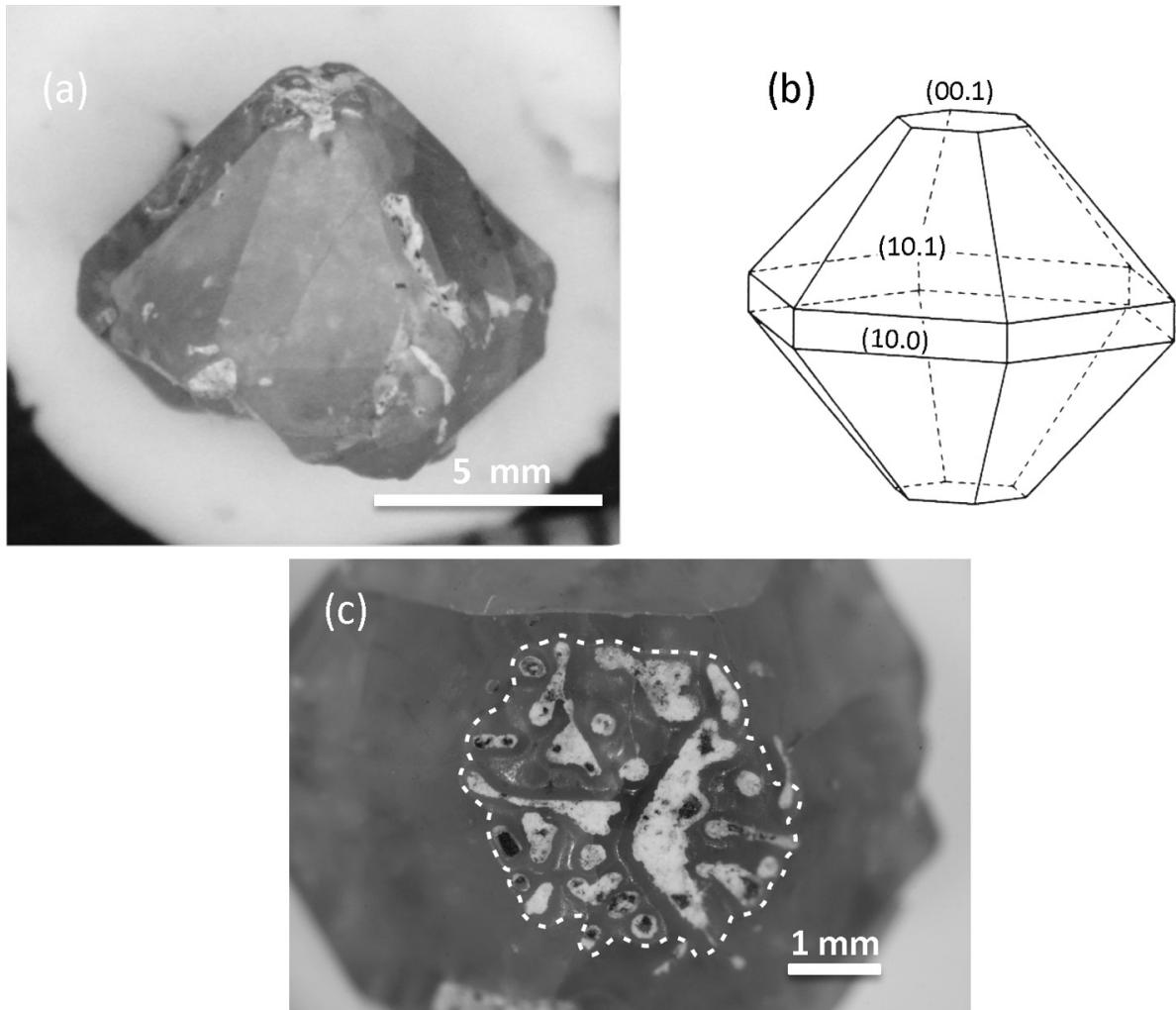

Figure 1. (a) Photograph of a separated crystal of high-quartz with the (00.1) basal face collected from the Nagatani area. (b) Crystal drawing of the high-quartz from Nagatani based on the precise reflection goniometry, showing the appearance of the basal face (quoted from Takada and Suesugi, 2004). (c) close-up of the (00.1) basal face of the highquartz crystal. Color version is available online from http://japan linkcenter.org/DN/JST.JSTAGE/ jmps/131022b. 
formation of the Arima Group and consists of biotite rhyolite welded lapilli tuff, tuff breccia and thin beds of tuffaceous clastic sediments (Matsuura et al., 1995).

The crystals of high-quartz from this locality exhibit a hexagonal bipyramidal habit with small prism faces and basal pinacoids (Fig. 1). According to Takada and Suesugi (2004), at least 127 of 144 crystals (88\%) examined by them have such basal faces. The surface morphologies of these basal faces were observed using a stereomicroscope, and showed the basal faces are full of cavities and ditches as if they were worm-eaten (Fig. 1c), and not exactly crystallographically flat $c$ faces. The crystals commonly exhibit rounded forms due to the dissolution process during the eruption of host magmas, and therefore, these basal faces also seem to have developed by a dissolution process as suggested by Takada and Suesugi (2004).

\section{OBSERVATION}

The internal growth-related zonal structure of the highquartz crystals from Nagatani area was first examined in details by employing the SEM-CL system. Bipyramidal crystals of high-quartz were cut parallel to (11.0) faces, so that growth bands must be vertical to the polish surface. CL images were obtained from these surfaces. The orientation of the polished surfaces was checked by the electron back-scattered diffraction (EBSD) technique. After observing the CL image on the surface, we made further grinding of that surface (about several hundreds $\mu \mathrm{m}$ in thickness) and then observed the CL image again on the new polished surface. By repeating this procedure, we obtain the polished surfaces of the crystals, parallel to (11.0) faces and through their center. The SEM-CL system used is based on an electron probe micro-analyzer (EPMA)
(JEOL: JXA-8105) and the emitted CL is detected by a photomultiplier (PMT: Hamamatsu Photonics R955) through a special light guide. Introduction of a photoncounting method enables us to obtain the high sensitive CL images (Shimobayashi et al., 2010). The acceleration voltage was $15 \mathrm{kV}$ and beam current was 3-10 nA.

The zonal structures in the high-quartz are characterized by the arrays of white and black bands in the panchromatic CL images (e.g., Fig. 2). Growth bands in the structures change their widths. Each CL image shows various complex growth zoning. Curved interface at some growth stages of the crystal seems to be characteristic in high-quartz, because the interface of low-quartz is essentially planar (e.g., Ramseyer and Mullis, 1990; Perny et al., 1992; Kawasaki et al, 2006). These curved interfaces must be resulted from the surface roughening of highquartz growing at high temperature unlike low-quartz. Growth habit is considered to be rounded bipyramidal shape with small and curved prism faces throughout the growth stage. Only in a few case, relatively flat basal faces perpendicular to the $c$ axis truncate the bipyramidal shape (as shown by an arrow in Fig. 2). The EBSD analysis confirms that the polished surface, from which the CL image of Figure 2 was just obtained, was almost perfectly cut parallel to the (11.0) section (Fig. 3). If the external shape is bipyramidal with no basal faces, the outline of the cross section would be bipyramidal with sharp apices in the (11.0) section, i.e., the truncated flat line perpendicular to the $c$ axis should not appear in this (11.0) section. Therefore, the truncated flat line shown in Figure $2 \mathrm{im}$ plies the appearance of the basal $c$ faces. Since the isochronal growth band with the flat $c$ face (labeled as 'band2 ') seems to be relatively sharp and smooth, the $c$ face should be directly developed by a growth process, not by
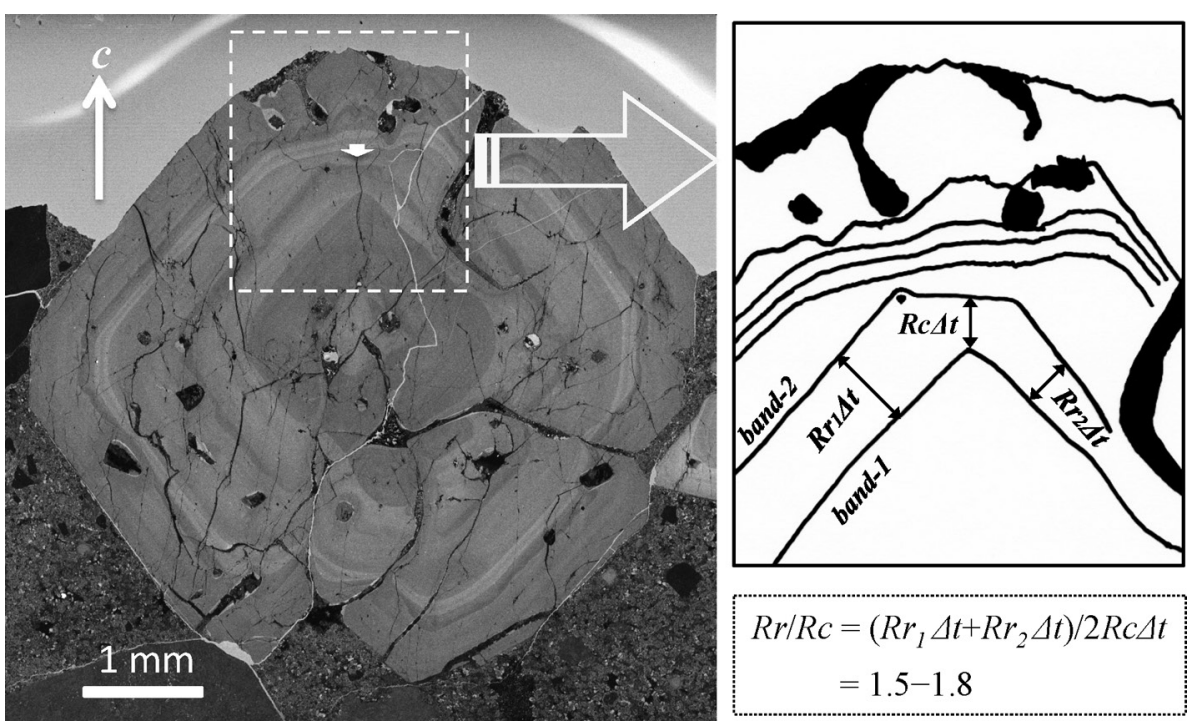

Figure 2. SEM-CL image of a crystal of high-quartz from the Nagatani area. The crystal was cut parallel to (11.0) face through its center. Trace of the flat basal (00.1) face perpendicular to the $c$ axis can be seen in a macroscopic scale as shown by white arrow. 

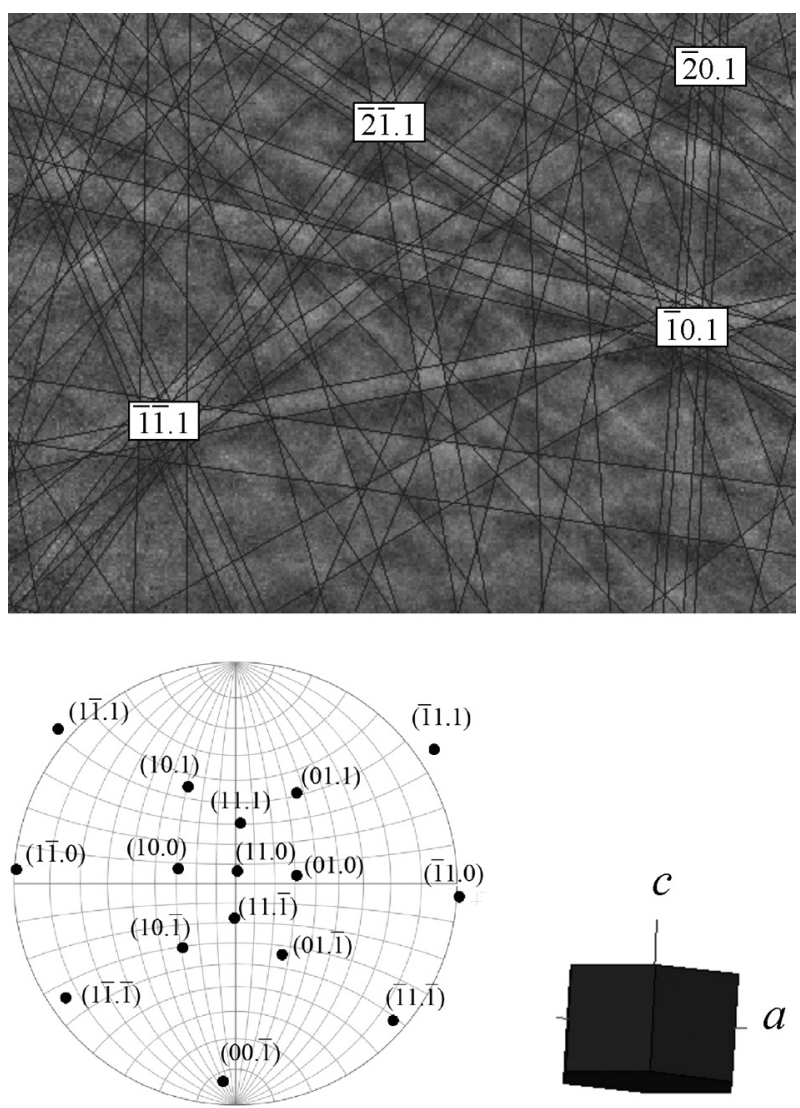

Figure 3. EBSD pattern (upper) overlapping the matching calculated pattern of high-quartz and the corresponding stereogram (lower) in which Miller indices of poles are marked, both of which show that the polished surface is almost parallel to the (11.0) face within a few degrees at most. Color version is available online from http://japanlinkcenter.org/DN/JST.JSTAGE/jmps/131022b.

a dissolution process.

\section{DISCUSSION}

The growth forms of polyhedral crystals strongly depend upon the normal growth rates $(R)$ of each crystal faces, e.g., crystal faces with large $R$ should disappear; only those with small $R$ will survive (Sunagawa, 2005). The anisotropy in the growth rates of synthetic quartz has been well understood (e.g., Fig. 2 of Iwasaki et al., 1997); Rm is the smallest, $R r$ and $R z$ are little larger and $R c$ is much larger than those of these $\mathrm{F}$-faces; i.e., the order being $R m$ $<R r<R z$ « $R c$. According to this figure, $R c$ is about 10 times faster than $R r$ (i.e., $R r / R c \sim 0.1$ ). However, growth bands in Figure 2 reveal that the morphological change from rounded bipyramidal shape with an apex (band-1) to that truncated by a basal face (band-2) seems to occur. Within this growth stage between 'band-1' and 'band-2', the $R r / R c$ ratio can be estimated to be $1.5-1.8$, the fact of which implies that the normal growth rate of the $c$ face,
$R c$, became relatively slower than those of the rhombohedral faces. The reason why a crossover between the growth rates $(R r>R c)$ occurred, and therefore as-grown $c$ faces appeared, remains unsolved, but two possibilities can be proposed; (i) $R r$ became much faster due to surface roughing at high temperature in the felsic magmas, and/or (ii) $R c$ became much slower if some impurities would be selectively adsorbed at the apex or on the small basal face and disturbed the normal growth in this direction.

\section{ACKNOWLEDGMENTS}

We appreciate Messrs. M. Takada and T. Ishibashi for guiding around the Nagatani area. We are grateful to Dr. T. Nagase and an anonymous reviewer, and Dr. K. Shinoda, an associate editor, for their constructive and critical reviews and editorial comments, respectively. We also thank Mr. K. Tanaka, who first started this study, for pleasantly providing us with his preliminary data.

\section{SUPPLEMENTARY MATERIAL}

Color version of Figures 1 and 3 is available online from http://japanlinkcenter.org/DN/JST.JSTAGE/jmps/ $131022 \mathrm{~b}$.

\section{REFERENCES}

Asada, R., Shimobayashi, N. and Kitamura, M. (2002) Equilibrium form of negative crystals in igneous quartz. Journal of Mineralogical and Petrological Sciences, 97, 59-69.

Hartman, P. (1959) La morphologie structurale du quartz. Bulletin de la Société française de Minéralogie et de Cristallographie, 82, 335-340.

Hartman, P. (1965) The non-uniform distribution of faces in a zone. Zeitschrift für Kristallographie, 121, 78-80.

Hartman, P. and Perdok, W.G. (1955) On the relation between structure and morphology of crystals. I, II, III. Acta Crystallography, 8, 49-52; 521-524; 525-529.

Hashimoto, A., Nagase, T., Kuribayashi, T. and Kudoh, Y. (2003) Growth mechanism of dipyramidal quartz. Abstracts of Mineralogical Society of Japan Annual Meeting, the Mineralogical Society of Japan, Sendai, 149 (in Japanese).

Hosaka, M., Miyata, T. and Sunagawa, I. (1995) Growth and morphology of quartz crystals synthesized above the transition temperature. Journal of Crystal Growth, 152, 300-306.

Iwasaki, F., Iwasaki, H. and Okabe, Y. (1997) Growth rate anisotropy of synthetic quartz grown in $\mathrm{Na}_{2} \mathrm{CO}_{3}$ solution. Journal of Crystal Growth, 178, 648-652.

Kawasaki, M., Nagase, T., Onuma, K., Katsumata, T. and Sunagawa, I. (2006) Appearance of basal faces in natural amethyst crystals from Four Peaks, Arizona. European Journal of Mineralogy, 18, 273-278.

Kitamura, M., Fudaki, M., Kyi Shwin and Shimobayashi, N. (1992) A cathodoluminescence microscope and its application to the study of growth zoning of minerals. Mineralogical 
Journal, 16, 108-116.

Matuura, H., Kurimoto, C., Sangawa, A. and Bunno, M. (1995) Geology of the Hirone district. With Geological Sheet Map at 1:50,000, pp.110, Geological Survey of Japan (in Japanese with English abstract, pp. 6).

Perny, B., Eberhardt, P., Ramseyer, K., Mullis, J. and Pankrath, R. (1992) Microdistribution of Al, Li, and Na in $\alpha$ quartz: Possible causes and correlation with short-lived cathodoluminescence. American Mineralogist, 77, 534-544.

Ramseyer, K. and Mullis, J. (1990) Factors influencing short-lived blue cathodoluminescence of $\alpha$-quartz. American Mineralogist, 75, 791-800.

Shimobayashi, N., Takaya, M., Nomoto, T. and Notoya, S. (2010) LRGB colour imaging of panchromatic SEM-CL images. Abstracts of the $20^{\text {th }}$ General Meeting of the International Mineralogical Association, pp. 692, Budapest, Hungary; Acta
Mineralogica-Petrographica, Abstract Series 6, 692.

Sunagawa, I. (2005) Crystals: Growth, Morphology and Perfection. pp. 295, Cambridge University Press.

Sunagawa, I. and Sugibuchi, A. (1986) Growth and post growth histories of high quartz as revealed by natural and laboratorical etching. Journal of the Japanese Association of Mineralogists, Petrologists and Economic Geologists, 81, 348-358.

Takada, M. and Suesugi, K. (2004) "High quartz with the basal (0001) faces found in the tuff breccia in the Nagatani area, Nose-town, Osaka Prefecture". "Pegmatite" (a literary coterie magazine), 69, 6-8 (in Japanese).

Manuscript received October 22, 2013

Manuscript accepted December 25, 2013

Manuscript handled by Keiji Shinoda 